\title{
A numerical model to predict residual stresses induced by ultrasonic shot peening treatment of Inconel 600
}

 \\ \& G. Douchet ${ }^{4}$ \\ ${ }^{1}$ LaMCoS, INSA-Lyon, CNRS UMR5259, F69621, France \\ ${ }^{2}$ LaMSID, UMR CNRS/EDF R\&D, France \\ ${ }^{3}$ AREVA NP, France \\ ${ }^{4} M R I, E D F R \& D$, France
}

\begin{abstract}
During a repair welding process, the ultrasonic shot peening (USP) process can be used as the final finishing step. The aim is to introduce compressive residual stresses on the surface of the welded area in order to prevent the occurrence of cracking. Although the numerical simulation method is able to predict the state of residual stress in the peened part, the 3D models of the real USP process, in which many successive and shifted impacts take place, is very delicate and costly in terms of computing time and memory space required. In this paper, we propose a method based first on the calculation of the averaged inelastic strain tensor in a local representative area, and second on the transfer of this inelastic strain field in order to simulate the USP process. Experiments, similar to the "Almen test", are performed on a thin plate of Inconel 600. Numerical results in terms of distortions and residual stresses are compared with the experimental data.
\end{abstract}

Keywords: Inconel 600, residual stress, ultrasonic shot peening, numerical simulation.

\section{Introduction}

Inconel 600, a nickel-based alloy, is widely used in construction of nuclear reactors due to its excellent mechanical properties at high temperature and 
corrosion resistance. The chemical composition of Inconel 600 is shown in Table 1:

Table 1: $\quad$ Chemical composition of Inconel 600, [\%].

\begin{tabular}{|c|c|c|c|c|c|c|c|c|c|c|c|c|}
\hline & $\mathrm{C}$ & $\mathrm{Mn}$ & $\mathrm{Si}$ & $\mathrm{Cr}$ & $\mathrm{Ni}$ & $\mathrm{S}$ & $\mathrm{P}$ & $\mathrm{Cu}$ & $\mathrm{Co}$ & $\mathrm{Ti}$ & $\mathrm{Al}$ & $\mathrm{Fe}$ \\
\hline Min & 0.01 & & & 14.0 & 79.99 & & & & & & & 6.0 \\
\hline Max & 0.05 & 1.0 & 0.5 & 17.0 & & 0.015 & 0.025 & 0.5 & 0.1 & 0.5 & 0.5 & 10.0 \\
\hline
\end{tabular}

The presence of nickel gives the alloy a relative higher resistance against corrosion. However, when the component is placed in a corrosive environment such as the primary circuit of a nuclear reactor, it becomes sensitive to the phenomenon of stress-corrosion cracking. Therefore it must be ensured that the level of residual stresses after welding process is lower than the triggering threshold of stress-corrosion cracking. In order to reduce such risks, ultrasonic shot peening can be used as the final finishing step in a repair process. The aim is to introduce compressive residual stresses at the surface of the welded area to prevent occurrence of cracking.

Very often the estimated residual stress fields are derived from a Finite Element (FE) simulation of a single impact or multi-impact at the same position [1]. So far, the 3D simulation of the real USP process, in which many successive and shifted impacts take place, is very delicate and costly in terms of computing time and memory space required.

In this paper, a 3D approach to determine the residual strain and stresses in a thin structure after the USP treatment is proposed. A combination of a semianalytical (SA) method and the finite element method is used. First, we present an experimental study of USP process, similar to the "Almen test", on thin plates made of Inconel 600 . In the second step, with the help of a 3D semi-analytical code, the plastic strain field due to the USP process is calculated and averaged in a local representative area of a semi-infinite domain. Then, this inelastic strain field is transferred into a FE model and the analysis are performed with the commercial package SYSWELD/SYSTUS [2] in order to predict the residual stress state in the thin plate after shot peening. Finally, the numerical and experimental results are compared.

\section{Experimental procedure}

The ultrasonic shot peening process is illustrated in Figure 1(a). A sinusoidal electric field is delivered by a generator. By using a piezo-transmitter, this electric energy is transformed into an ultrasonic vibration, then amplified by a booster. This energy is thereafter transferred into kinetic energy stored by the balls when they are projected by the "sonotrode". The balls are confined in a chamber on top of which the specimen is fixed. Similar to the "Almen test", the specimen is fixed by four bolts as illustrated in Figure 1(b). During the process, the successive impacts will change the mechanical properties of the material and generate a compressive residual stress field at the surface and in the close 
sublayer of the treated plate (Figure 1: 1(c)). At the end of the process, it can be observed a small curvature of the plate before the bolts are removed. After the removal of the bolts, the residual stress field is redistributed. This bends the specimen to a more convex arc versus the peened surface, as illustrated in Figure 2 .

Several parameters can influence the results of the experimentation. They are principally related to the balls (material and diameter) and to the process (shot

(a)

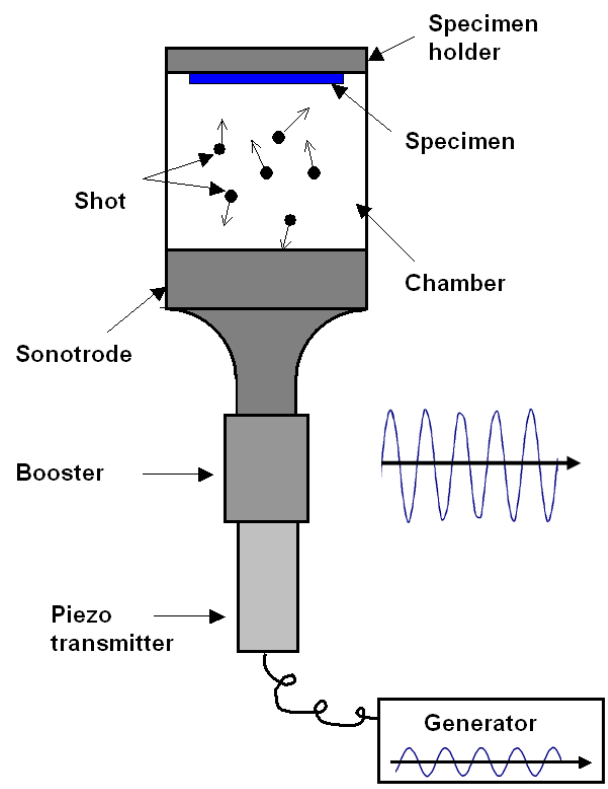

(b)

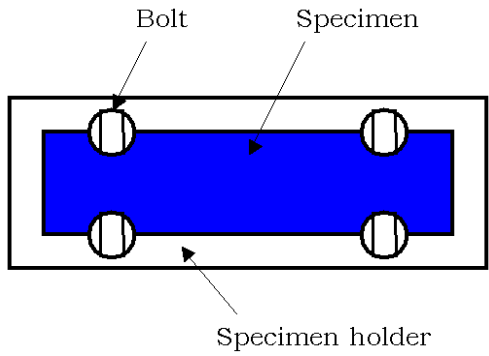

(c)

Surface treated by USP

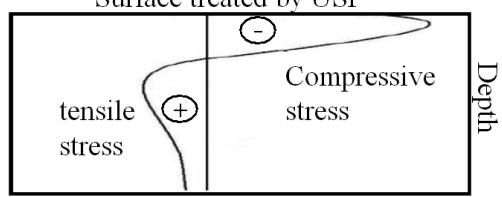

Figure 1: Experimental device - (a) overall view, (b) fixation system of the specimen by bolts, (c) residual stress profile due to USP treatment.

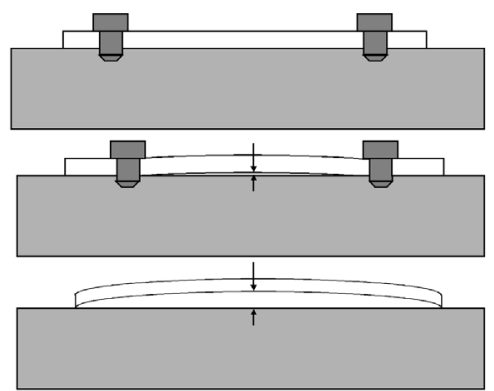

Before treatment

After treatment

when bolts are fixed

After treatment when bolts are removed

Figure 2: $\quad$ Formation of arc height due to USP treatment. 
velocity and peening coverage rate). The effects of some parameters have been investigated in the simulation of a single impact with the FE method in [3, 4]. For the multi-impact modeling, an analytical approach to determine the arc height induced by shot peening as well as a relationship between the arc height and the residual stress field is proposed in $[5,6]$. It can be deduced from the literature that the most important parameters in the USP process are the shot velocity and the peening coverage rate.

In this paper, the USP experiments are carried out on thin plates made of Inconel 600 with dimensions $60 \times 18 \times 2 \mathrm{~mm}^{3}$. The specimens are initially given a stress relieving heat treatment in order to reduce as much as possible the stresses caused by machining. The balls of diameter $4 \mathrm{~mm}$, are made of bearing steel AISI 52100 (also known as $100 \mathrm{Cr} 6$ in Europe). The piezoelectric transducer emits the ultrasonic wave at $20 \mathrm{kHz}$. The amplitude of the sonotrode is $25 \mu \mathrm{m}$. It is assumed here that the coverage rate is proportional to the exposure time. According to Figure 3: 3, the exposure time to reach a coverage rate of $100 \%$ is approximately $4 \mathrm{~min} 30 \mathrm{~s}$ for specimen $\mathrm{N}^{\circ} 3$. Therefore the coverage rate is $200 \%$ for specimen $\mathrm{N}^{\circ} 4$.

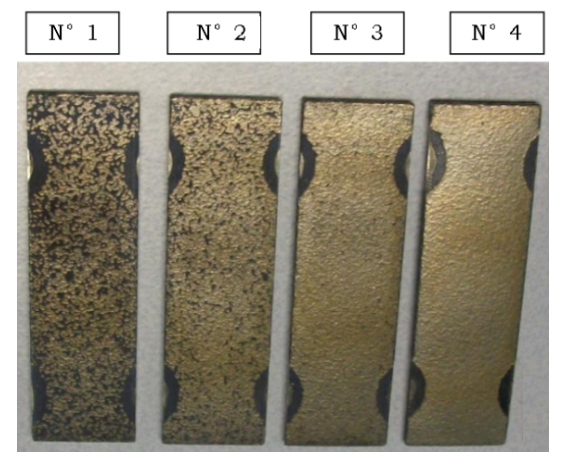

\begin{tabular}{|c|c|c|}
\hline$N^{\circ}$ & $\begin{array}{c}\text { Exposure } \\
\text { time }\end{array}$ & Coverage \\
\hline 1 & $\mathrm{t}(1 \mathrm{~min} 8 \mathrm{~s})$ & \\
\hline 2 & $2 \mathrm{t}$ & \\
\hline 3 & $4 \mathrm{t}$ & $\approx 100 \%$ \\
\hline 4 & $8 \mathrm{t}$ & $\approx 200 \%$ \\
\hline
\end{tabular}

Figure 3: $\quad$ Specimens peened with different exposure times (the specimens are initially painted before the USP treatment).

Two types of measurements are realized after the USP treatment. The residual stresses at the surface of plates are measured with the X-ray diffraction (XRD) method. The material is then removed by electropolishing to measure the stresses along depth. The residual arc height of the specimen is measured by a $3 \mathrm{D}$ coordinate-measuring machine (CMM).

\section{Numerical modeling}

The USP process can be considered as many elastic-plastic indentations at different surface points, created by an impactor with a spherical tip, during a given exposure time and with a random position of impacts. Note that at the impact velocities encountered during USP process, it could be assumed that inertial effects can be neglected. 
The simulation of all impacts in a USP process when the coverage rate is higher than $100 \%$ is almost unfeasible because of the computing time that would be required. Nevertheless, after saturation or for a sufficiently high coverage rate, it could be assumed that the plastic strain and the residual stress will only vary along the depth. Consequently, we can consider a local area instead of the whole treated surface to calculate the residual strain and stress field in order to minimize the number of impacts simulated. Some researchers have used a rectangular pattern with four dimples produced by the impactors [7]. The local representative area chosen in this study consists in a triangle where the centers of three successive impacts are linked. All three impacts are normal to the surface, and the centers are equidistant as shown in Figure 4: 4. As the distance between impacts increases, the peening coverage decreases.

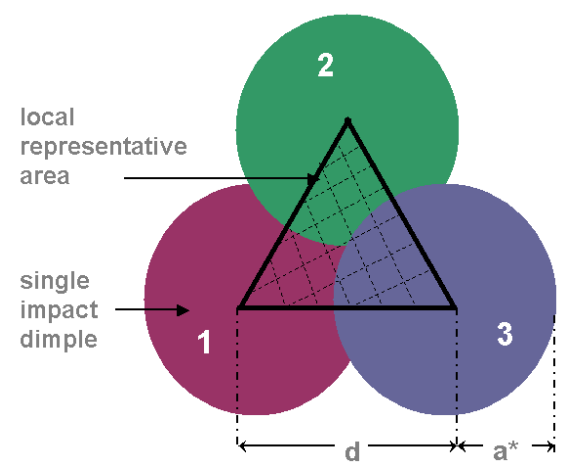

Figure 4: Local representative area and sequence of impacts (the pattern presents a $100 \%$ peening coverage rate).

By definition, the peening coverage rate is the ratio between the impacted surface and the initial surface. It can therefore be expressed as follows:

$$
T=\frac{2 \pi}{\sqrt{3}}\left(\frac{a^{*}}{d}\right)^{2}
$$

where $\mathrm{T}$ defines the coverage rate, $\mathrm{d}$ the distance between the centers of impacts and $\mathrm{a}^{*}$ the radius of dimples caused by the plastic contact. This radius is determined numerically and corresponds to the maximum radius of contact between the elastic impacting sphere and the elastic-plastic impacted half-space during the first impact.

Another important parameter is shot velocity. Since the movements of the balls in the chamber are random, the collisions between them or with the side walls of the chamber can change the direction and the velocity of the balls. It is assumed here that all the impacts will occur at the same velocity and an average velocity is considered to simulate the three local impacts. This average velocity is taken as the maximum initial velocity of the sonotrode, which can be calculated as follows: 
Considering that the sinusoidal harmonic signal delivered by the generator is:

$$
x(t)=A \sin \omega t
$$

where $\mathrm{A}$ is the amplitude and $\omega$ represents the pulsation.

It yields:

$$
\frac{d x}{d t}=A \omega \cos \omega t
$$

According to eqn (3), the maximum initial velocity is:

$$
v_{\text {ini_max }}=2 A \pi f
$$

where $f$ represent the frequency of the sonotrode.

The initial theoretical shot velocity calculated with our experimental parameters equals $4 \mathrm{~m} / \mathrm{s}$. This value is considered as the average velocity of the impacts during the process and will be used as input in the simulations.

The simulations that are performed are three-dimensional, based on a semianalytical method originally proposed to solve elastic-plastic contact problems [8-10]. The calculations are realized on a semi-infinite body discretized in cuboids of constant size. The method has been extended to solve impact problems and the computing time is significantly decreased by the use of the FFT3D method [11]. However, the hypothesis of half-space is not suitable to predict the residual state within thin structures treated by USP. Therefore the semi-analytical method will be only used for the simulation of USP for thick structures and a technique to transfer the inelastic strain field will be used.

In order to determine the residual stress field in the thin plate, the plastic strain field is averaged at each depth of the triangular pattern as shown in Figure 5. Then the average inelastic strain tensor is transferred into the Gauss points of a finite element model of the plate where the boundary conditions correspond to those of the experimentations. Finally, the residual stresses are recalculated by solving the static equilibrium equation when the bolts are removed.

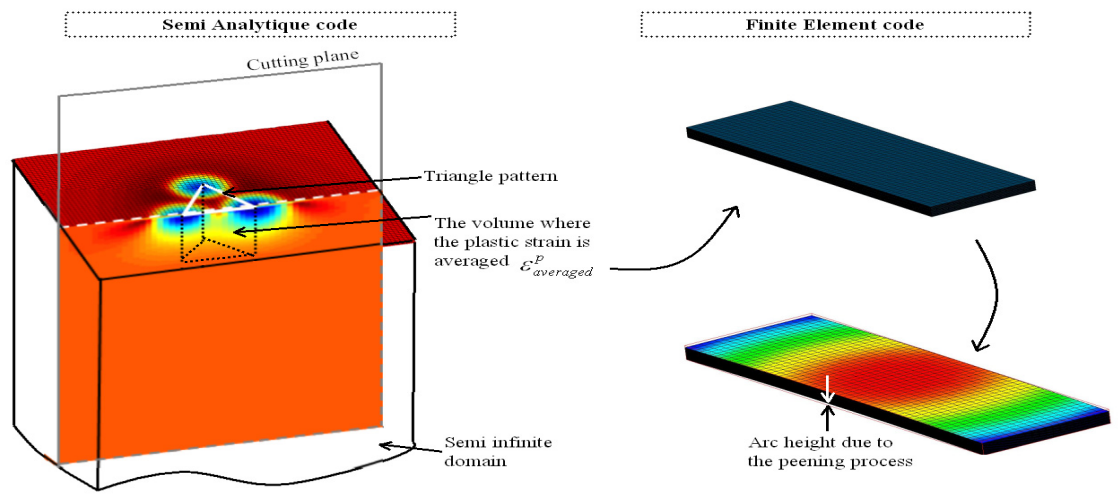

Figure 5: Transfer of the averaged inelastic strain tensor from the SA model to the FE model. 
In this paper, the final results of the FE analysis are derived from calculations performed with the code SYSTUS/SYSWELD. The mesh is set up by 8-node linear bricks. The hardening law of material is assumed isotropic and the parameters' identification of the material model is based on monotonic tensile tests.

\section{Results and discussion}

The residual stresses are measured at the centerline of the specimens in the longitudinal and transversal directions. The impact velocity is set to $4 \mathrm{~m} / \mathrm{s}$ and the peening coverage rates of $100 \%$ and $200 \%$ are studied. Comparison between Figures 6 and 7 shows a good agreement between the numerical results and

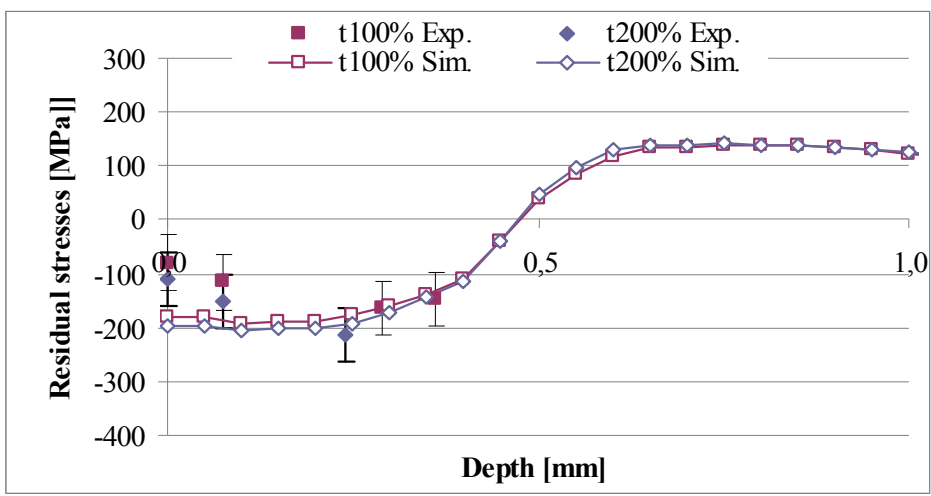

Figure 6: Comparison between numerical results and experimental data in terms of residual stresses along the longitudinal direction.

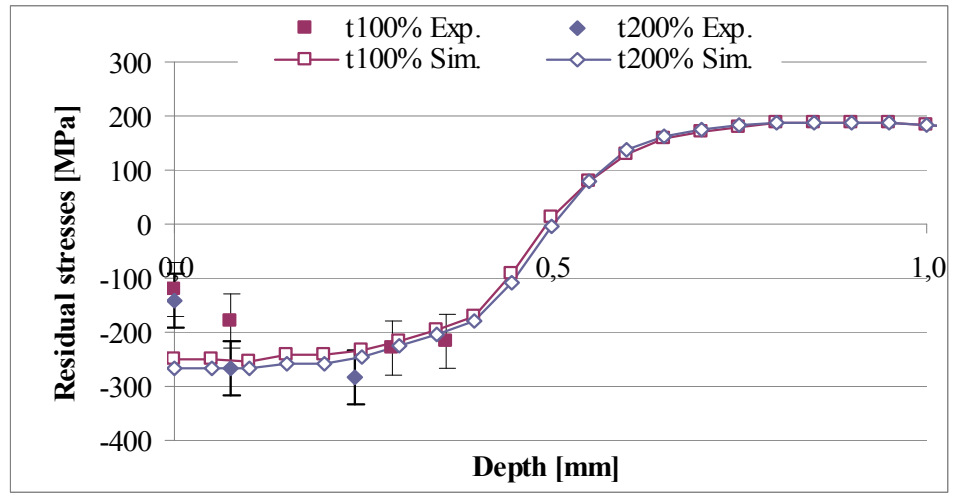

Figure 7: Comparison between numerical results and experimental data in terms of residual stresses along the transversal direction. 
experimental data. The simulations permit also to estimate the depth where the maximum compressive stress is found and its magnitude. Some differences can be also observed in the surface layer $100 \mu \mathrm{m}$ thick. These differences can be attributed to some inaccuracy in the identification of the hardening law, uncertainties in the measurements or more likely the insufficiency of stress relieving to reduce the initial hardening due to surface machining. The full width at half maximum (FWHM) is plotted as a function of the distance from the surface in Figure 8: 8. It can be seen that the hardening level is more important at the surface than in depth and that it does not decrease after the heat treatment. Note that the higher the coverage is, the more important the hardening at the surface of the plate will be and the less the initial conditions (hardening related



Figure 8: $\quad$ FWHM measurements before and after stress relieving.

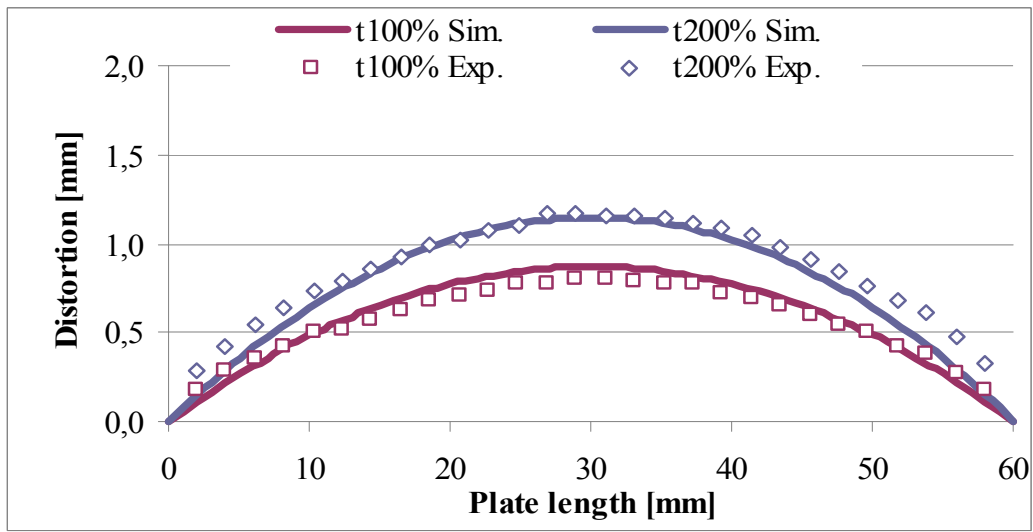

Figure 9: Comparison between numerical results and experimental data in terms of deformation distortions (deformed shape along the longitudinal direction). 
to machining) will be influential. Moreover, it can be observed that the stress level is greater in the transversal direction than in the longitudinal one. This can be explained by the clamping conditions (location of bolts, see Fig. 1(b)).

Figure 9: 9 provides a comparison of the deformed shape of the plate (when the bolts have been removed). A very good agreement can be observed. It could be also noticed that the distortion increases when increasing the coverage rate (or the USP treatment time).

\section{Conclusion}

A multi-impact model, able to predict the level of residual stresses and the arc height of a thin structure after ultrasonic shot peening treatment, has been proposed. This method is based on a semi-analytical code which has the advantage of saving considerable computing time compared to finite element models without sacrificing the quality of results. Then, the numerical results are compared with the experimental data. The residual stresses calculated are in good agreement with those measured. Deflection of the specimen after shot peening can also be correctly estimated.

Ultimately, the method will be applied to a welding part with subsequent residual stresses to analyze how initial stresses may influence the build-up of compressive residual stresses by ultrasonic shot peening.

\section{References}

[1] Miao, H.Y., Larose, S., Perron, C. \& Lévesque, M., On the potential applications of a 3D random finite element model for the simulation of shot peening, Advances in Engineering Software, 40, pp. 1023-1038, 2009.

[2] Systus/Sysweld User's manual, ESI Group, 2010.

[3] Schwarzer, J., Schulze, V. \& Vohringer, O., Finite element simulation of shot peening - a method to evaluate the influence of shot peening parameters on surface characteristics, Proc. of 8th international Conference of Shot Peening (ICSP), pp. 507, 2002.

[4] Bhuvaraghan, B., Sivakumar M. \& Bob, M., Optimization of the fatigue strength of materials due to shot peening: A Survey, International Journal of structural changes in solids - Mechanics and Applications, 2(2), pp. 33-63, 2010.

[5] Guagliano, M., Relating Almen intensity to residual stresses induced by shot peening: a numerical approach, Journal of Materials Processing Technology, 110, pp. 277-286, 2001.

[6] Miao, H.Y., Larose, S., Perron, C. \& Lévesque, M., An analytical approach to relate shot peening parameters to Almen intensity, Surf. Coat. Technol. 205, pp. 2055-2066, 2010.

[7] Kim, T., Lee, J., Lee, H. \& Cheong, S., An area-average approach to peening residual stress under multi-impacts using a three-dimensional symmetry-cell finite element model with plastic shots, Materials and Design, 31, pp. 50-59, 2010. 
[8] Jacq, C., Nélias, D., Lormand, G. \& Girodin, D., Development of a three dimensional semi-analytical elastic-plastic contact code. Journal of Tribology, 124, pp. 653-667, 2002.

[9] Nélias, D., Boucly, V. \& Brunet, M., Elastic-plastic contact between rough surfaces: proposal for a wear or running-in model. ASME Journal of Tribology, 128(2), pp. 476-485, 2006.

[10] Nélias, D., Antaluca, E., Boucly, V. \& Cretu, S., A 3d semi-analytical model for elastic-plastic sliding contacts. ASME Journal of Tribology, 129(4), pp. 761-771, 2007.

[11] Zhou, K., Chen, W.W., Keer, L.M. \& Wang, Q.J., A fast method for solving three-dimensional arbitrarily shaped inclusions in a half space. Computer Methods in Applied Mechanics and Engineering, 198(8-12), pp. 885-892, 2008. 